\title{
DIE TWEETERREINELEER VAN NATUUR EN BONATUUR
}

\author{
Dr. B. J. van der Walt
}

Ons let op die volgende punte:

Historiese agtergronde

Verskillende tipies tweeterreinelere

Spanninge tussen die twee terreine

Skrifmatig- wysgerige kritiek op die tweeterreineleer.

\section{Historiese agtergronde}

Die tweeterreineleer is afkomstig van die onderskeid tussen profaan (of sekulêr) en sakraal (of heilig) wat reeds in die pagane Griekse denke aangetref word. Veral K. J. Popma he ${ }^{1}$, insiggewende gegewens na vore gebring soos o.a. die oorsprong van die woord „profaan" van die Latyn pro + fanum d.w.s. die heiligdom. Wat die betekenis van die woord "sakraal" betref, gee ons graag die woord aan M. P. Nilson: ,In Latin the word sacer had both senses; it means both sacred and ,accursed'. The Greek language has the corresponding idea but not the word ... The connecting link is that both the sacred and the accursed are withheld from common use; they are handed over to the gods, whether to their care or to their wrath"2.

Die volgende gegewens is net so insiggewend: "The idea of taboo is the root and origin both of that which is sacred and of that which is accursed. There has only been a displacement of the casual motive: the essential of sancitity is possession by a god. That which is under a curse is also dedicated to a god, but to his anger and vengeance"s.

Hieruit blyk dus dat die onderskeid tussen profaan en sakraal nog verder as die Griekse denke teruggevoer kan word en wel tot die taboeidee van die sg. primitiewe denke. Dit blyk verder duidelik dat die sakrale met die goddelike, wat afgesonderd van die alledaagse bestaan, verband hou.

Die vroeë Christene het met die kenteoretiese probleem van geloof en wete geworstel. Hulle het tot helderheid probeer kom oor hoe presies die verhouding tussen hulle eie Christelike geloof en die heidense wysbegeerte behoort te wees. Baie populêr was die gedagte dat die heidense denke as praeparatio evangelica gesien moet word. Soos wat God die Jode met die Ou Testament opgevoed het sodat hulle Christus sou aanvaar, so het $\mathrm{Hy}$ die Grieke met hulle wysbegeerte vir dieselfde einddoel voorberei. Die Ou Testament en die Griekse denke is as 't ware twee riviere wat albei in die Nuwe Testament uitmond. Die Evangelie is hiervolgens dus alleen die vervolmaking van wat potensieel reeds by die heidene aanwesig was.

Om die rede mag dan ook van die heidense denke gebruik gemaak word. Die heidense denke is alleen ' $n$ minder volmaakte of kinderlike stadium teenoor die volwassenheid van die Christendom. Die Antieke wysbegeerte vereis nie algehele bekering en verandering nie, aangesien dit baie waarheidselemente bevat wat alleen om vervolmaking vra. Op dié wyse word die Grieks-Romeinse denke as voortrap tot die Christendom gesanksioneer. 
Die worsteling met die probleem van die verhouding tussen wete en geloof het uiteindelik in die skema natuurlik-bonatuurlik uitgekristaliseer. Hierin bied die Patristiese denke egter nie iets oorspronkliks nie, aangesien dit bloot 'n Christelike modifikasie van die eeue-oue pagane dualisme van profaan en sakraal is. Juis die aanvaard'ng van hierdie skema maak die Christelike sintesedenke moontlik.

Daar kan dus gesê word dat die kenteoretiese geloof-weteprobleem tot ' $n$ ontologiese tweedeling (op die gebied van die nietransendente in die geval van dualistiese ontologieë) aanleiding gegee het. Hierdie tema word gedurende die Middeleeue (o.a. by Thomas van Aquino) tot die natuur-genadeonderskeid omgebou. Dit beteken dat die ontologiese tweedeling as oplossing vir 'n kenteoretiese probleem nou weer antropologies versmal word, aangesien goddelike genade op die mens betrekking het. (By die leer van mens as beeld van God word volgens hierdie skema tussen 'n natuurlike beeld en genadebeeld onderskeid gemaak.).

Die toepassing van die duplex ordo van natuur en genade is eg. ter nie daartoe beperk nie maar geld die hele lewe van die mens. Die mens se geloof, sy godsdiens, sy hele religieuse lewe word van sy sg. natuurlike, alledaagse bestaan afgesonder. Die Bybel en alles wat met God en Christendom verband hou, word tot iets bonatuurliks verklaar.

Hieruit blyk duidelik die deurwerking van die eeu-oue skema van profaan en sakraal. Aangesien die gewone mens ver weg van die heilige lewe ${ }^{4}$, en nogtans die Bybel, kerk ens. vir sy saligheid nodig het, ontstaan die noodsaaklikheid van sg. tussenfigure soos priesters en teoloë wat die sakrale nader aan die profane kon bring sonder dat die profane daardeur opgehef word, aangesien dit 'n eie reg van bestaan het. (Soos uit die oorspronklike betekenis van die woord sacer hierbo geblyk het, kan die sakrale ook 'n bedreiging vir die gewone mens inhou.)

\section{Verskillende tipes tweeterreineleer}

Aangesien die natuur-genadetema primêr 'n onderskeid binne die mensbeskouing is, spreek dit vanself dat verskillende mensebeskouinge tot uiteenlopende tipes tweeterreinelere aanleiding sal gee. By 'n grondige tipologie, van die verskillende tweeterreinelere sal dus die ontologiese en antropologiese voorveronderstellings, waarin hulle ten diepste wortel, in berekening gebring moet word.

Aangesien die natuur-genadetema in die praktyk egter meestal in 'n teologiese gedaante voorkom, is dit dikwels uiters moeilik en selfs onmoontlik om 'n suiwer wysgerige klassifikasie te bied. In die geval moet dan volgens 'n minder fundamentele beginsel tussen die verskillende variasies van tweeterreinelere onderskei word. Ter illustrasie word hier alleen kortliks verduidelik hoe die tweeterreinelere ingedeel kan word volgens die kriterium van hoe ingrypend die gevolge van die sondeval beskou word. Hoe daar volgens hierdie indelingsbeginsel te werk gegaan word, blyk uit die skematiese voorstelling van vier hooftipes waarvan twee die ekstreme standpunte na 
albei kante aantoon en twee die meer gebalanseerde tussenposisies aandui. (Tussen hierdie vier hooftipes is talle variasies moontlik wat hier buite rekening gelaat word).

1. Uiterste : NATUUR (is alles want - Genade ongeskonde)

$1.1 \quad$ : Natuur (is prinsipieel goed - slegs iets verlore)

Bemiddelingspogings

2.1

: Genade (is die belangrikste maar het tog 'n aanknopingspunt nodig)

2. Uiterste : GENADE (is alles want natuur is radikaal verdorwe) (is feitlik nie nodig nie).

- Genade (is van minder belang, want dit gee alleen iets wat verlore is terug).

- Natuur (radikaal verdorwe maar iets daarvan het tog as aanknopingspunt oorgebly).

- Natuur (so verdorwe dat dit van geen betekenis is).

Volgens die een uiterste (1) word die klem sterk op die natuurpool gelê, aangesien die effek van die sondeval heeltemal onderskat word. Die mens kan volgens sy natuurlike kapasiteite in die regte rigting lewe en met sy feitlik ongeskonde rede die waarheid - ook dié aangaande God - bereik. Die genade van God en die wedergeboorte deur die Heilige Gees is feitlik nie nodig nie maar van bloot addisionele betekenis.

Die ander ekstreme standpunt (2) gaan van die radikale verdorwenheid van die mens a.g.v. die sondeval uit. Soveel klem word op die genadepool gelê dat die wedergeboorte feitlik as 'n totaal nuwe skepping en nie as 'n herstel van die bestaande gesien word nie. Die bonatuurlike openbaring is die enigste redding van die mens, want uit homself kan hy die waarheid nooit ken nie. Hoe die genade volgens hierdie visie egter ookal beklemtoon word, dit bly in dialektiese spanning saam met die gedegradeerde natuurpool bestaan. Daarom is dit geen Skrifmatige visie nie, al mag dit ook op die oog af so lyk en aan die reformatoriese standpunt van byvoorbeeld Calvyn herinner.

Meestal word, nadat die twee ekstreme oplossings van 'n probleem uitgetoets is, die oplossing in 'n tussenposisie gesoek. Ook in hierdie geval verkies die meeste denkers wat die tweeterreineleer aanhang 'n meer gematigde bemiddelingsposisie.

$\mathrm{Na}$ aan die eerste uiterste lê die standpunt (1.1) wat nog die grootste klem op die natuur lê maar tog die genade 'n groter rol laat speel, omdat die natuur wel inherent goed is maar daar tog iets verlore geraak het. Die mens vorder met sy natuurlike kragte 'n hele ent totdat God hom met die genade dit wat hy verloor het as toegif terugskenk en so vervolmaak.

'n Verswakking van die tweede ekstremistiese standpunt (2.1) kom na aan die pasgesketste variant. Dit lê nog wel die hoofklem op die genade, maar die natuur kom almeer tot sy reg. Die natuur is wel diep in sonde geval, maar nie so radikaal dat daar niks goeds in oorgebly het nie. 'n Res van die goeie maak dit moontlik dat die 
menslike kennis nog sekere waarheidsmomente kan bereik. Hierdie "res" kan 'n aansluiting vir die genade bied. Die genade is wel die belangrikste, maar die natuur bied tog 'n gebrekkige aanknopingspunt.

\section{Spanninge tussen die twee terreine}

Soos reeds aangetoon, was die natuur-genadetema die oplossing vir die geloofweteprobleem wat ontstaan het as gevolg van die vroeë Christene se worsteling met die verhouding tussen heidense denke en Christelike geloof. Die vraag is of die natuur-genadetema werklik die probleem van die verhouding tussen pagane Griekse denke en Skrifgeloof opgelos het. Myns insiens is die probleem deur die toepassing van die tweeterreineleer aan die een kant oorvereenvoudig en het dit aan die ander kant ook ontsettend gekompliseerd geraak.

Die probleem is in die eerste plek te simplisisties opgelos, aangesien beide heidense en Christelike denke (as die laere en hoëre komponente) in één denkskema saamgevat is. In hierdie skema word albei gebiede wel nie van gelyke waarde geag nie (die heidendom is alleen die voortrap tot die Christendom), maar die heidendom word tog gesanksioneer deurdat dit in één skema met die Christendom saamgedink word.

Om aan ' $n$ dubbelfokusbril gewoond te raak is aan die begin moeilik, maar later word dit gewoonte. Om voortdurend in twee wêrelde te beweeg, mag aan die begin onnatuurlik aandoen maar bied lateraan die maklikste oplossings. In die tweeterreineleer word die hele werklikheid volgens die dubbelvisie betrags. Die sintesetrein kan nie sonder hierdie dubbelspoor voortbeweeg nie. Moontlik bied die feit dat die natuur-genadetema die probleem van die verhouding tussen Christendom en heidendom so simplisisties oplos die verklaring vir die geweldige populariteit daarvan dwarsdeur die geskiedenis van die Christelike denke tot op die huidige dag ${ }^{6}$.

Met die natuur-genadetema word die probleem egter nie opgelos nie. Presies die omgekeerde effek word bereik as wat ons sou verwag het. 'n Mens sou veronderstel dat, nadat Christendom en heidendom sinteties saamgevat is, kommunikasie tussen beide veel gemakliker sou verloop as wanneer die antitese tussen beide duidelik gestel is. Die natuur-genadetema bied mos 'n gemeenskaplike ontmoetingsvlak (nl. die terrein van die natuur) tussen Christen en heiden. Feit is egter dat deur die sintese die kommunikasie juis bemoeilik ${ }^{7}$ is. Volgens die natuur-genadetema het Christendom en heidendom mekaar nie, soos die positiewe en negatiewe pool van twee magnete, vasgegryp nie. Aangesien die heidendom ook positief waardeer word, stoot die twee, soos die positiewe pole van twee magnete, mekaar eerder af. Dit blyk duidelik uit die volgende.

In ooreenstemming met die tweeterreineleer word geloof en wete, Teologie en Wysbegeerte teenoor mekaar gestel. Die Christenteoloog en heidense wysgeer behoort tot twee verskillende gebiede. Nadat heiden en Christen tot verskillende vlakke of terreine gelokaliseer is, word gepoog om kontak tussen die twee te bewerk. Aan die heiden moet tog ook die Evangelie verkondig word! 
Die dialektiese spanning is duidelik. Aan die een kant is die antitese tussen natuur en genade gerelativeer en is beide in die een denkskema saamgevat. Aan die ander kant blyk dat natuur en genade, Wysbegeerte en Teologie tog in 'n spanningsrelasie staan. Dit is egter nie 'n korrekte nie maar 'n kunsmatige antitese tussen twee terreine, wat nou die spanning veroorsaak.

Die valse territoriale spanning is vir die voorstanders van die tweeterreineleer egter reël. Die noodsaaklike kontak tussen beide kan alleen bereik word deur 'n brug van die een na die ander te bou. Die vanselfsprekend Christelike Teologie het die brug na die gebied van die Wysbegeerte, of die kerk na die terrein van die wêreld nodig. Aangesien die gebied van die natuur die voortrap tot die genade vorm, kan die brugbouaktiwiteit egter alleen hiervandaan 'n aanvang neem - hoewel die behoefte daartoe op die terrein van die bonatuurlike lê. Die Natuurlike Teologie vorm die laaste of hoogste deel van die Wysbegeerte en kan met reg as Teologiese Filosofie aangejui word. Die naam Natuurlike Teologie dui egter aan dat dit 'n Teologie op die terrein van die natuur, teenoor 'n Bonatuurlike Teologie op die terrein van die genade is.

In 'n sekere sin is die Natuurlike Teologie dus die resultaat van die feit dat die Christelike Teologie volgens die tweeterreineleer, as Bonatuurlik verklaar is. (Dit hang weer saam daarmee dat die Bybel, die veld van ondersoek van die Bonatuurlike Teologie, as bonatuurlike openbaring beskou is.) Omdat die Christelike, Bonatuurlike Teologie esoteries bo die alledaagse werklikheid verhef is, het 'n Natuurlike Teologie as pendant nodig geword. Die voor-die-hand-lig. gende implikasie is dan ook dat, om alleen met die Natuurlike Teologie te breek, en nog steeds 'n Bonatuurlike Teologie te handhaaf, geen werklike oplossing bied nie. Albei teologieë sal vir 'n nuwe visie i.v.m. die Teologie, waarin die tweeterreineleer nie as uitgangspunt geld nie, plek moet maak.

Die Natuurlike Teologie bestaan dus kragtens die spanningsrelasie tussen twee gebiede wat as foutiewe oplossing vir die veel dieperliggende religieuse antitese angebied word. Dit lê voor die hand dat hoe groter die dialekteise spanning tussen die twee terreine gesien word $^{3}$, hoe noodsaakliker die brugwetenskap word, maar dat dit terselfdertyd ook moeiliker word om so 'n wetenskap tot stand te bring9. Is die spanning tussen die natuur- en genadepool kleiner ${ }^{10}$, dan kan die kontak by wyse van 'n Natuurlike Teologie makliker bereik word, maar die noodsaaklikheid is dan ook nie meer so groot nie.

Die Natuurlike Teologie, basterkind van Teologie en Wysbegeerte, wat a.g.v. die spanning tussen die twee bestaan, erf die dialektiese tweespalt wat tussen sy ouers bestaan het. Dit openbaar 'n totale skisofrenie: dit bestaan nie net kragtens die dialektiese spanning nie maar word deur die spanning sy bestaansmoontlikheid ook ontneem indien die spanning te groot sou raak.

Die Natuurlike Teologie in Christelike milieu is onafskeidelik aan een of ander vorm van tweeterreineleer verbonde. Die enigste werklike oplossing is om die tweesporige denkwyse self te laat vaar en nie om ' $n$ nuwe variasie op dieselfde tema te probeer nie. Die eien- 
aardige is egter dat hierdie insig in die massa literatuur oor die Natuurlike Teologie feitlik ontbreek. Uitsprake soos die volgende twee is uiters seldsaam.

H. Dooyeweerd sê in 'n diskussie met die Thomistiese natuurlike Teologie: "Het religieuze grondmotief van natuur en genade, dat heel de Thomistische wijsbegeerte beheerst, eist in zijn typisch Romanistische conceptie een onderbouw van een autonome natuurlijke godskennis onder de openbaringstheologie"11.

E. Kinder sien die tweeterreineleer as die vitium originis raak as hy sê: "Natürliche Gotteserkenntnis und übernatürliche Gottesoffenbarung stehen in Ergänzungsverhältnis $\mathrm{zu}$ einander. Dahinter steht die statische 'zweistöckige' Weltbild von Natur und Ubernatur". Verderaan dieselfde: "Der Begrif 'natürliche Theologie' ist in der christlichen Tradition nur einmal mit dem 'zweistöckigen' Weltbild von Natur und Ubernatur verbunden"12.

\section{Skrifmatig-wysgerige kritiek op die tweeterreineleer}

A.g.v. die feit dat die antitese tussen dit wat die Woord van God openbaar en dit wat die heidense denke leer, nie radikaal gesien is nie maar sinteties saamgedink is, is die karakter van die antitese ook nie korrek ges'en nie. Die stelling kan ook omgekeer word: aangesien die antitese nie korrek gesien is nie, kon die radikale karakter daarvan nie ges:en word nie.

Voor clie sondeval het die mens in 'n religieuse verhouding tot God gestaan wat sy hele lewe, en nie net 'n sekere gebied, geraak het nie. Na die sondeval het die mens nie die religieuse gerigtheid verloor nie, want dit hoort tot sy wese.

Hy het nou alleen in 'n negatiewe, afvallige religieuse verhouding tot God te staan gekom a.g.v. gehoorsaamheid aan die Satan. Hierdie nuwe religieuse rigting raak ook die mens se hele bestaan. $\mathrm{Na}$ die sondeval en die verlossing deur Jesus Christus is die goed-kwaadbepaaldheid op die ganse skepping van toepassing.

Die fout van alle vorme van tweeterreinelere is dat die religieuse visie van die sondeval deur 'n meer ontologiese gesigspunt oorwoeker word. Hiervolgens verloor die mens by die sondeval iets, nl. die bonatuurlike genadedeel van sy bestaan. Sonde word dus nie radikaal as 'n aspostatiese krag gesien nie maar alleen negatief as die afwesig. heid van of gebrek aan die goeie (genadedeel), 'n privatio boni. Sonde dui alleen op synsonvolmaaktheid of verlies van goddelikheid en daarom is die mens ook nog tot veel goeds in staat ${ }^{13}$ - al kos dit soms veel inspanning. A.g.v. 'n aangebore natuurlike verlange is die mens na die val volgens Thomas van Aquino bv. nog op God gerig.

By die verlossing skenk God die verlore bonatuurlike genade (synstekort of goddelikheid) alleen aan die mens terug. Waar sondeval die verlies aan iets is, is verlossing die teruggawe van iets. Die sondaar is die mens minus die bonatuurlike deel en die verloste is die mens plus die domum superadditum.

Die verskil tussen die heiden en die Christen is dan ook alleen dat die Christen die plus van die genade addisioneel ontvang het. Die heiden leef alleen op die gebied van natuur en genade. Verlossing volgens hierdic beskouing raak dus nie die hele lewe van die 
mens nie, dit beteken nie radikale en totale verandering van rigting, religieuse ommekeer nie, aangesien dit alleen op 'n sekere gebied beirekking het. Verder hou verlossing volgens hierdie visie ook die vergoddeliking van die mens in ${ }^{14}$.

Die beswaar teen die tweeterreineleer ${ }^{15}$ is dus dat die antitese a.g.v. die sondeval en die verlossing daarna tot sekere terreine gelokaliseer word of ontologies volgens synsgebiede afgebaken word. Hierdie kritiek mag nie verkeerd geinterpreteer word asof die antitese 'n blote "geestelike" saak sou wees nie. Daar sit wel 'n waarheidsmoment in die gedagte dat die antitese gelokaliseer kan word, want hoewel van religieuse aard het dit tog ook konkrete gevolge. Die antitese word ook sigbaar en kan geïnstitusionaliseer word. 'n Christelike huwelik behoort, ten spyte van die vele gebreke, as sodanig tot die koninkryk van God en 'n nie-Christelike behoort, ten spyte van die goeie dinge wat daarin gevind mag word, tot die ryk van die bose. Hiermee word egter ook nie bedoel dat die skeidslyn altyd duidelik sigbaar is en dat daar simplisisties volgens 'n wit-swartskema onderskeid gemaak kan word nie. Voorbeelde van mengvorme is legio. Juis daarom kan lokalisasie soms gevaarlik wees.

Die kritiek teen die tweeterreineleer is dat ons hier met 'n onjuiste lokalisasie in die struktuur van die menslike bestaan te doene het. Die religieuse tweespalt tussen die lewe volgens die Gees van Christus en die lewe in ongehoorsaamheid kan in die werklikheid nooit presies en definitief op die wyse van die tweerykeleer gelokaliseer word nie. Dit gaan veel dieper. In plaas van tweërlei allesbepalende religieuse rigting (vir of teen God) in dieselfde skepping, tree hier as 't ware twee lewens op wat nie alleen verskillende wyses van lewe is nie, maar dialekties, bo of langs mekaar staande soorte of gebiede van lewe is.

A. Troost het egter aangetoon dat die ryk van God en dié van die Satan nie in bepaalde terreine gelokaliseer kan word nie. Dit gaan in die antitese nie om twee aparte wêrelde nie maar om ' $n$ tweestryd binne dieself le wêreld: „Erkennt men echter de eenheid van Gods Woord en werk in schepping en verlossing, dan kan men niets ter wêreld en ook niets in deze menselijke sameleving en haar structuren (van nature) onttrekken zien aan Gods totalitaire heerschappij.

"De concrete ontrekking van de (subjectieve zijde der) samen. levingsorde aan de heerschappij van Gods wil (normatiewe zijde) . . mag niet theologisch, ontologisch en anthropologisch worden geprojekteerd tot twee zijns-structuren, twee werelden of twee rijken ...

"Wij hebben hier ... te doen met een onjuiste localisatie binnen de structuur van die menslijke existentie, van de in werkelijkheid nooit precies, en zeker niet só te localiseren geestelike tweespalt tussen het leven naar de Geest van Christus en het leven van 'het vlees'. In plaats van 'tweërlei beginsel' (Kuyper) van en in hetzelfde door God geschapen leven, treden hier twee levens op, die niet slechts in concreto verschillende wijzen van leven zijn, maar twee (dialectisch) naast elkaar staande soorten van leven"16.

Behalwe dat ons nie van genade voor die sondeval reeds wil spreek nie ${ }^{17}$, staan genade ook nie teenoor die natuur nie maar teenoor die toorn van God ${ }^{18}$. Genade staan ook nie teenoor sonde nie, 
maar genade met betrekking tot sonde beteken vergewing. Soos wat aan die kant van God genade die teenoorgestelde van toorn is, is aan die kant van die mens vergeefde sonde teenoor sonde wat toegereken word ${ }^{19}$.

Volgens die Woord van God is 'n tweerykeleer (die ryk van God en die van die Satan) wel moontlik maar geen tweeterreineleer nie. In die tweeterreineleer gaan dit om 'n ontiese tweedeling in die lewe van die mens, lerwyl dit in die tweerykeleer om die religieuse antitese tussen die ryk van die lig en die duisternis gaan. Die geskiejenis het egter aangetoon hoe maklik dit kan gebeur dat die Skrifmagtige gedagte van 'n tweerykeleer deur die onskrifmagtige idee van 'n tweeterreineleer beïnvloed kan word, sodat die ryk van die Antichris in 'n terrein van die natuur en die ryk van Christus tot die terrein van die genade gelokaliseer word.

\section{VERWYSINGS}

1. Cf. Popma, "Natuur en genade". Philasophia Reformata, 36:93 - 124, 1971 asook Eliade, Das Heilige und das Profane.

2. Nilson, M.P. A history of Greek Religion, p. 81.

3. Ibid., p. 82. H. J. Rose bied 'n soortgelyke verklaring van die woord: ". . . the word sacer, which is very much like Polynesian term ,tapu', has a double meaning. A res sacra is a piece of property of some kind made over to a god, and therefore, as we should call it, holy or sacred; but a homa sacer, a man thus severed from everyday life, is rather a person accursed, left for the gods concerned, or some particular god, to deal with as may seem fit to divine wisdom". Religion in Greece and Rome, p. 230. Cf. in die verband ook Kuitert, Profaan. Bezinning, 12(4): 205, 1975. Volgens hom is die idee van die sacrum as 'n soort reservaat vir die goddelike 'n primitiewe idee wat nie deur die Bybel aanvaar word nie.

4. Die tweeterreineleer hang onmiskenbaar ook met die dualistiese denke saam waarvolgens die transendente God (net soos die sakrale sfeer) op 'n oneindige afstand, ver weg van die gewone (nie-transendente) mens staan.

5. Die volgende begrippepare is dikwels uitvloeisels daarvan: koninkryke van die werreld - koninkryke van God, sekuler - religieus, outonome mens soewereine God, die God van die wysgere - die God van die Bybel, God die Skepper - God die Verlosser, aarde - hemel, kind van die aarde - kind van die hemel, sigbare - onsigbare, vlees - gees, leke - klerus, wereld kerk, staat - kerk, keiser - pous, politikus - prlester, vader - monnik, moeder - non, huwelik - selibaat, algemene of natuurlike openbaring -besondere of bonatuurlike openbaring, wete - geloof, handele - geloof, Natuurlike Teologie - Bonatuurlike Teologie, Wysbegeerte - Teologie, universiteit - seminarie, klaskamer - kapel, sekulere of natuurlike wet - kanonieke of goddelike (bonatuurlike) wet, outonoom - teonoom, horisontaal - vertikaal, tydelik - ewig, kardinale (natuurlike) deugde - Christelike (bonatuurlike) deugde, navorsing - aanbidding, menslik - Christelik, lieede tot die wereld - liefde tot God, sedelikheld - vroomheid, Fisika - Metafisika, natuurgeskiedenis - heiligsgeskiedents, "terrein" van die algemene genade - "terrein" van die besondere genade, histo- 
ries - bohistories, kosmiese liefde - hemelse liefde, wêreldlik - geestelik, burger - Christen, kultuur - religie, wetenskap - godsdiens, hiermaals - hiernamaals, sekulêr - heilig, profaan - sakraal, wêreldlik - bowêreldlik, eindige - oneindige, uiterlik - innerlik, geloof in die wêreld - geloof in God, wêreld - God, immanensie - transendensie, materieel - geestelik, menslike wysheid - goddelike wysheid ens. ens.

B. Troost spreek in diê verband van die geestelike mag van die tweeryke. leer en waarsku tereg dat ons dit nie in die magnetiese veld van die onskriftuurlike dialektiek van natuur-bonatuur moet waag nie, want dit kan deur geen enkele teologiese konstruksie oorwin word nie. Cf. "Bezinning over koninkrijk Gods". Mededelingen van de Vereniging voor Calvinistische Wijsbegeerte, September 1971, p. 12, 14, 16.

7. Dit is te verstane, want die koninkryk van God word hiervolgens soos 'n oliedruppel op die water, 'n vreemde werklikheid buite en bo die aan ons bekende werklikheid.

8. Cf. die twee uiterstes ( 1 en 2) wat in die diagram hierbo gegee is.

9. Daarom is vele gematigdes, wat die uiterstes na weerskante as "ketterye" afwys, geneig om nie van 'n Natuurike Teologie in die geval van byvoorbeeld $K$. Barth (alle klem op genade) of $P$. Tillich (alle klem op natuur) te spreek nie - in alle geval nie in die tradisionele sin waarin die woord gebesig word nie.

10. Cf. die twee middelposisies (1.1 en 2.1) in die bogenoemde diagram.

11. Dooyweerd. Philosophia Reformata 17: 181, 1952.

12. Kinder. Das vernachlăssigte Problem der " natürlichen" Gotteserfahrung in der Theologie. Kerugma und Dogma 9: 321, 1963.

13. Cf. Meuleman, G. E. „Natuur en genade”. (In: Protestantse verkenningen na "Vaticanum II", p. 72). Die rede waarom die Rooms-Katolieke nie kan aanneem dat die mens na die sondeval radikaal verdorwe is nie, gee Meuieman op p. 77 soos volg aan:

"Omdat het voor de mens sonder genade moeilijker is op natuurlijk gebied het goede te doen, spreekt men wel van een "verwonding" van de natuur als gevolg van de zonde van Adam. Men wil echter niet spreken van een radicaal verdorven natuur. Dan zou er ook geen aanknopings. punt meer zijn voor de genade en zou het ook nie kunnen komen tot de door de Kerk geleerde samewerking van genade en vrije wil."

14. Cf. Jacobs. Incarnatie en genade, p. 7, 8, 22 en 29 . Smit stel die verskil tussen die Rooms-Katolieke en Protestantse visie t.o.v. die genade soos volg: ". . . voor de Rooms-Katholiek is de genade allereerst een de mens ingestorte kwaliteit, waardoor hij in beginsel de goddelijke natuur deelachtig wordt en waardoor de gehele natuur tot godvormigheid wordt verheven. Voor die Reformatie daarentegen is de genade primair de vrije gunst Gods waarin Hij de zonde vergeeft". De moderne Protestantse visie op de geschiedenis. (In De zin der geschiedenis voor geloof en rede, p. 243.)

Tereg sê $O$. Noordmans in die verband dat die Bybel die boek van die menswording van Christus en nie van vergoddeliking van die mens is nie. Natuur en genade bij Rome, p. 3. Verder voeg hy daaraan toe dat by sodanige vergoddeliking van die mens nooit 'n egte ontmoeting tussen God en mens kan plaasvind nie, aangesien die onderskeid tussen God en mens feitlik opgehef word. (p. 12). 
15. Jacobs skets op verskillende plekke in Incarnatie en genade die verskil tussen die Skriftuurlike begrip genade en die Rooms-Katolieke visie daarvan. Cf. veral p. 32 en 51 - 3. Cf. ook Wentzel. Natuur en genade. Een introductie in en confrontatie met die jongste ontwikkeling in de Rooms-Katholieke theologie inzake dit thema waarin hy op p. 322 die Bybelse begrip natuur en op p. $344-45$ die Bybelse begrip genade omskrywe. Vir die Skri.tuurlike betekenis van die begrip "ganade" cf. verder ook Polman in Christelijke Encyclopedie, III, p. $154-5$.

16. Troost. De openbaring Gods in de maatschappelijke orde. Philosophia Reformata, 34 : 12, 1969 Elders se hy: "De verselfstandiging van de zonde, zoals dat plaats vind in elke variant van die twee-rijken-leer, trekt een scheur door de schepping, tast de integrale worteleenheid van al het geschapene in Christus aan, en suggereert dat er nog ergens een duimbreed domein is dat niet rechtstreeks tot het rijksgebied van Christus behoort." "Bezinning over het koninkrijk Gods". Mededelingen van de Vereeniging voor Calvinistische Wijsbegeerte, Sept. 1971, p. 13. Troost beklemtoon dit in hierdie artikel dat die hele skepping sonder meer in Christus die ryk van God is. Daar is slegs één ryk van Christus en dit is die geskape kosmos en alles wat dit insluit.

17. Cf. Wentsel, op cit., p. 306.

18. Cf. Wentsel, op cit., p. 306 waar hy stel dat genade volgens die skrif (God se guns, vergewing, vernuwing, inwoning van die Heilige Gees) die teëpool van die strawwende geregtigheid van God is. "De tegenstelling sonde-genade is bepaald een bijbelse antithese. En deze dient die tussen natuur en bovennatuur te vervangen." (p. 371) Cf. ook p. 430 waar hy konstateer dat in die Rooms-Katolieke teologie natuurlike en bonatuurlik en in die Protestantse teologie sonde en genade mekaar se metgeselle of teëvoeters vorm.

So ook Popma: die Skrif magtig ons alleen om as teënstelling tot natuur "onnatuur(lik)" en as teëstelling van genade, sonde te sien Cf. Philosophia Reformata, 36:109. 1971. Dieselfde by Vollenhoven, Het Calvinisme en de Reformatie van de Wijsbegeerte, p. 45 - 7; De Graaf, Philosophia Reformata 1:18, 1936 en De Graaf, The educational ministry of the church, p. 32.

19. Cf. hiervoor die werk van Vollenhoven in die voorafgaande voetnoot vermeld. 